\title{
REBELDIA E SEMEADURA (ASPECTOS DA SEMANA DE 22)
}

\author{
Maria Augusta Fonseca \\ mabfonseca@usp.br
}

À memória de Mário da Silva Brito e de João Luiz Lafetá

Em "Nota sobre vanguarda e conformismo" (O pai de família e outros estudos), Roberto Schwarz assevera e indaga:

Sabe-se que progresso técnico e conteúdo social reacionário podem andar juntos. Essa combinação, que é uma das marcas de nosso tempo, em economia, ciência e arte, torna ambígua a noção de progresso. Também a noção próxima de vanguarda, presta-se à confusão. $\mathrm{O}$ vanguardista está na ponta de qual corrida? (1978, p. 43)

As colocações de Schwarz, postas aqui em foco, servem para dimensionar e alavancar problemas que, nesta leitura, envolvem a Semana de Arte Moderna e o movimento modernista brasileiro. Para abordar e desenvolver o tema, pretendo articular alguns textos valorativos e questionadores, cujas mediações fecundas permitem compreender o tema no contexto em que se desenvolveu e pensar a sua atualidade. Afinal, estamos no início do século XXI, temporalmente distantes da Semana de Arte Moderna, realizada no Teatro Municipal de São Paulo em fevereiro de 1922. E, claro, distantes também dos propósitos que mobilizaram intelectuais e artistas num movimento que pretendia a 
renovação das artes (em especial da literatura) no Brasil, país que, àquela altura, ingressava no "século da gasolina".

Para isso, começo por um recorte extraído da conferência "O movimento modernista”, proferida por Mário de Andrade em 1942, mostrando que aquela reviravolta ocorrida no campo das artes ultrapassou seus intentos, na medida em que trouxe à luz dos acontecimentos problemas de fundo da vida brasileira. A explanação de Mário é longa, penetrante e implacável. $O$ trecho destacado vale como ilustração: "Manifestado especialmente pela arte, mas manchando também com violência os costumes sociais e políticos, o movimento modernista foi o prenunciador, o preparador e por muitas partes o criador de um estado de espírito nacional" (ANDRADE, 1974, p. 231).

Quase dez anos antes desse balanço crítico e autocrítico, outro modernista propulsor de mudanças, Oswald de Andrade, já havia encetado seu juízo fulminante, resumindo e escancarando o atraso cultural, as mazelas institucionais, o estado de espírito alienante (em parte também incluindo a América Latina) que presidiram as três primeiras décadas do século XX, como se lê no prefácio que escreveu em 1933 para Serafim Ponte Grande:

A situação "revolucionária" desta bosta mental sul-americana, apresentava-se assim: o contrário do burguês não era o proletário - era o boêmio! As massas, ignoradas no território e como hoje, sob a completa devassidão econômica dos políticos e dos ricos (2000, p. 55).

Na mesma sequência, depois de salvar Macunaíma (1928) como obra originária de nosso solo, Oswald volta à carga, sequer poupando sua própria obra:

A valorização do café foi uma operação imperialista. A poesia Pau Brasil também. Isso tinha que ruir com as cornetas da crise. Como ruiu quase toda a literatura brasileira "de vanguarda", provinciana e suspeita, quando não extremamente esgotada e reacionária. Ficou da minha este livro. Um documento. Um gráfico. O brasileiro à-toa na maré alta da última etapa do capitalismo (2000, p. 57).

Desse ataque, nem a vanguarda europeia (que pressupunha nosso diálogo com a atualidade) foi poupada. Por isso, indaga: "Quem sabe se a alta do café não ia colocar a literatura nova-rica da semicolônia ao lado

\footnotetext{
1. A expressão "no século da gasolina” foi extraída de uma crônica de Menotti del Picchia, "A 'bandeira' futurista” (1921), transcrita por Mário da Silva Brito em História do Modernismo Brasileiro Antecedentes da Semana de Arte Moderna, obra da qual este artigo é devedor.
} 
dos custosos surrealismos imperialistas?” (ANDRADE, 2000, p. 57) Algum tempo mais tarde, Oswald irá retomar suas críticas recolocando questões e procurando mostrar outras facetas do movimento e a diversidade de problemas nele envolvidos. Com essas diretrizes em vista, vale articular e examinar o movimento e a Semana de Arte Moderna por alguns de seus aspectos conflitantes.

Um pequeno retrospecto mostra que, em fevereiro de 1922, a imprensa paulistana aguardava com ansiedade a anunciada "Semana de Arte Moderna", prestes a acontecer no imponente Teatro Municipal de São Paulo. Na programação, além das exposições de arte, estavam previstas três apresentações, que ocorreriam nos dias 13, 15 e 17, com recitais de piano, leituras de poemas e fragmentos de romances, bem como leituras de propostas estéticas. No palco, iriam se apresentar Oswald e Mário de Andrade, Guilherme de Almeida, Menotti del Picchia, Ronald de Carvalho, Villa-Lobos, Graça Aranha, entre outros. No hall, seriam exibidos trabalhos de Anita Malfatti, Di Cavalcanti, Zina Aita, Ferrignac, John Graz, Oswaldo Goeldi, Victor Brecheret.

Com foco nos acontecimentos, no dia estabelecido para a abertura da Semana, saiu um artigo de jornal, assinado por Oswald de Andrade, comparando os integrantes do grupo a "boxeurs na arena". A expressão indicava que tanto ele como os seus companheiros anteviam problemas. Daí o articulista apelar para uma recepção de espírito aberto, em face das novidades que pretendiam apresentar. Com percepção contrária, porém, antecipadamente ajuizava: "Nós, pelo acolhimento da plateia de hoje, julgaremos da cultura de nosso povo. Pois sabemos, com Jean Cocteau, que quando uma obra de arte parece avançada sobre o seu tempo, ele é que de fato anda atrasado" (ANDRADE, 2000, p. 86).

Já é bem conhecida a reação que partiu da plateia quando hoje se conta a história da Semana de Arte Moderna. Para dizer o mínimo: xingamentos, vaias, pateadas. Mesmo assim, os participantes resistiram, seguindo até o último dia das apresentações, com a leitura de trechos de Os condenados de Oswald de Andrade, declamação de "Os sapos" de Manuel Bandeira e da "Ode ao burguês" de Mário de Andrade, como exemplos de uma variada lista. Entre os discursos proferidos, destaca-se aqui (por ser pouco lembrado) aquele em que Menotti del Picchia faz o elogio da mulher moderna, em mais uma manifestação do arejamento que proclamavam: "Queremos uma Eva ativa, bela, prática, útil no lar e na rua, dançando tango e datilografando uma conta corrente; aplaudindo a noitada futurista e vaiando os tremilicantes e ridículos poetaços de frases inçadas [...]" (apud BRITO, 1976, s. p.). 
Menotti prossegue: “[...] a mulher é a colaboradora inteligente e solerte da batalha diuturna, e voa no aeroplano, que reafirma a vitória brasileira de Santos Dumont e cria o mecânico de amanhã que descobrirá o aparelho destinado à conquista dos astros" (apud BRITO, 1976, s. p.).

Ainda que problemática, a proposta era audaz para o meio acanhado. Visava colocar a figura feminina em consonância com seu tempo, alinhada ao espírito ousado que entendiam ser o de sua modernidade. No entanto, nota-se que a liberdade reivindicada favorecia a mulher da elite ou a da classe média, com acesso àqueles bens proclamados. O mesmo se pode pensar em relação ao trabalho, uma vez que, na mesma cidade de São Paulo, a mulher do povo batalhava arduamente nas fábricas, como operária, ou em casa, como prestadora de serviço informal - costureira, lavadeira, passadeira, bordadeira, etc. - para garantir sustento familiar. Como ruptura de amarras, porém, a iniciativa era válida, porque implicava na possibilidade de alargar direitos na esfera do universo feminino: uma reivindicação de cidadania.

Se pensarmos à luz das primeiras décadas do século XX no Brasil, a mulher, de qualquer estrato social (mesmo a operária), já nascia como uma cidadã parcialmente "incapaz", ficando sob a tutela do pai, ou então do marido. $\mathrm{O}$ direito de votar foi conquista posterior à década de 1920. Nesse rol de restrições, também o estudo estava reservado ao universo masculino. Cursar uma universidade era sonho impossível para a mulher. Quando muito, antes do casamento, algumas entre as mais favorecidas financeiramente podiam frequentar a Escola Normal, que formava professoras para o curso primário. Na classe média, estudar piano representava uma alternativa para a mulher poder sair de casa e se educar. Mas, no Conservatório Dramático e Musical da cidade de São Paulo, por exemplo, depois do artigo de Oswald - "O meu poeta futurista" -, o respeitado professor Mário de Andrade foi visto com horror pelos pais de família, impróprio para as jovens, perdendo assim várias de suas alunas. E isso em 1921.

Passada a borrasca de 22, alguns integrantes da Semana avaliaram os acontecimentos como frutíferos, apesar dos escândalos e dos entraves. Sérgio Milliet, por exemplo, entendeu aquele esforço conjunto não como algo isolado, mas como "um apelo aos outros desconhecidos do Brasil que, a poder de coragem e de perseverança, conseguem esta coisa surpreendente: dar a São Paulo, a cidade do café, a cidade nouveau riche, noitadas de arte moderna” (MILLIET, 2000, p. 128).

Vinte e dois anos mais tarde, no artigo "Gênese da Semana de Arte Moderna", Oswald de Andrade resumiu em perspectiva crítica a relevância das manifestações, combinadas às contradições inevitáveis 
daquele movimento que, afinal, brotou dos anseios de uma elite culta. Para o "arauto da Semana",

[...] a primeira fase da revolução literária brasileira não deixaria de ser a exata eclosão de uma sensibilidade burguesa, atingida enfim na selva semi-colonial da América, pela era da máquina, pela era burguesa e futurista da máquina. [...] Fomos burgueses em 22 e tínhamos de ser. Isso já era uma notável superação (ANDRADE, 1944, p. 13).

De modo bem estruturado, em História do Modernismo Brasileiro I - Antecedentes da Semana de Arte Moderna (1959), o crítico e historiador Mário da Silva Brito coligiu, examinou e equacionou dados para mostrar diferentes fatores e forças atuantes no processo de renovação artística no país, que culminou com a Semana de 22. Assim, ao longo de dez anos, Brito entrevistou artistas e intelectuais; realizou pesquisas em jornais de época; consultou livros e documentos, cedidos por Rubens Borba de Moraes, Carlos Drummond de Andrade, Oswald de Andrade. Entre os entrevistados estão Mário e Oswald de Andrade, Anita Malfatti, Tarsila do Amaral, Menotti del Picchia, Guilherme de Almeida, Carlos Drummond de Andrade. Com esse raro e importante material de fonte primária, o historiador perfilou comportamentos de grupos e ações individuais, traçou interesses comuns e apresentou outros divergentes. Registrou encontros de intelectuais em livrarias, rôtisseries, exposições. Nesse mapeamento pioneiro, Brito recolheu manifestos de artistas e informações sobre debates, produções individuais, reuniões, ciclos de conferências, buscando adensar informações sobre o evento inaugural do movimento modernista brasileiro. Ainda, pôs em perspectiva a vida política e econômica do país, contemplou as lutas sociais mais relevantes no período, além de avaliar aspectos da vida cotidiana no parque industrial paulista, palco da Semana de Arte Moderna. No balanço final, o crítico aproximou a batalha de 22 da exposição de Anita Malfatti, em 1917, para ele, o "estopim" do modernismo:

Os jovens escritores e artistas aguardavam, somente, uma oportunidade qualquer para tomar de assalto - e definitivamente - a liderança das letras e das artes. É preciso não esquecer que, já em 1920, Oswald de Andrade anunciava para 1922, ação dos novos que fizesse valer o nosso Centenário. Essa oportunidade surgiria com a ideia da realização da Semana de Arte Moderna. Graça Aranha empenharia a importância do seu nome para o êxito da arremetida da juventude intelectual, e foi esse o seu principal papel nos sucessos que ocorreriam no ano em que o Brasil completava um século de autonomia política. A ideia da Semana de Arte Moderna [...] estava assentada ao fim de 1921. O terreno, arroteado pela polêmica e pelas atitudes dos modernistas nesse ano, era propício e a semeadura, iniciada desde 1917, com a 
exposição de Anita Malfatti, ia produzir, enfim, os seus frutos. Outra etapa da história cultural brasileira iria ser inaugurada (BRITO, 1964, p. 322).

Para Mário da Silva Brito, aqueles jovens que se rebelaram contra o próprio meio conseguiram sacudir e abalar mentalidades retrógradas, buscando caminhos frutíferos de transformação. Não por acaso, os costumes, as mulheres, a cultura brasileira, a língua de expressão local, a literatura atrasada, que estavam no cerne dos questionamentos, ganharam destaque na sua obra.

Emblemática na história literária brasileira, a Semana de 22 marcou nossa entrada na modernidade artística, como uma "tecla de sonoridade diferente", no entender de Oswald de Andrade. Nesse processo de atualização estética, o movimento local tanto buscou diálogos com as vanguardas europeias do começo do século XX como procurou conhecer em profundidade a cultura do país, de onde emanavam questões substantivas para a compreensão do modo de ser local. Antonio Candido traduziu essa conjunção de problemas nos seguintes termos:

Os nossos modernistas se informaram pois rapidamente da arte europeia de vanguarda, aprenderam a psicanálise e plasmaram um tipo ao mesmo tempo local e universal de expressão, reencontrando a influência europeia por um mergulho no detalhe brasileiro. É impressionante a concordância com que um Apollinaire e um Cendrars ressurgem, por exemplo, em Oswald de Andrade (CANDIDO, 1973, p. 121).

Na visão do crítico, o "mergulho no detalhe brasileiro" torna o movimento local singular. Esse diferencial também levou Mário de Andrade a concluir que "de todas as tentativas de modernização artísticas do mundo, talvez a que achou melhor solução para si mesma foi a brasileira" (1983, p. 17). Nessa avaliação, Mário de Andrade esclarece:

Todo o segredo de nossa revolta estava em dar uma realidade eficiente e um valor humano para nossa construção. Isso estamos descobrindo. Ora, o maior problema atual do Brasil consiste no acomodamento de nossa sensibilidade nacional com a realidade brasileira, realidade que não é só feita de ambiente físico e dos enxertos de civilização que grelam nele, porém comportando também a nossa função histórica para conosco e social para com a humanidade (1983, p. 18).

Compreendia assim que os nossos modernistas tinham a seu favor a possibilidade de desbravar um mundo ainda novo. Isso implicava na percepção aguda da nossa realidade, compreendida num universo periférico em relação à Europa, requerendo com isso preocupações distintas. O alcance desta visão certeira não é trivial. 
À luz dessas questões, pode-se dizer que a Semana de 22 foi válvula propulsora de um movimento transformador no Brasil. O período áureo, que fertilizou o terreno de nossa literatura, irá se desenvolver até 1929, ano marcado por crises profundas. O "segundo tempo modernista", que abarca os anos 30 e 40 (em parte), colheu produtos oriundos de "nosso solo", abrangendo um novo período conturbado no campo social, político, econômico no Brasil e no mundo.

Visto em perspectiva, ainda que reduzido a um grupo da elite culta, o movimento modernista fez história em seu tempo. Desse modo, entende-se a Semana de Arte Moderna como parte de um processo articulado à vida desajustada do país, em que pesa o estado geral de atraso, compreendendo a exploração social, reviravoltas econômicas, instabilidade política, sempre a desencadear convulsões que afetaram e afetam (para melhor ou pior) a vida dos cidadãos. O campo das artes e da cultura não se aparta desse terreno minado. Neste sentido, uma análise de Antonio Candido nos ajuda a configurar aspectos dessa questão:

\footnotetext{
[...] o Modernismo não foi apenas um movimento literário, mas, como tinha sido o Romantismo, um movimento cultural e social de âmbito bastante largo, que promoveu a reavaliação da cultura brasileira, inclusive porque coincidiu com outros fatos importantes no terreno político e artístico, dando a impressão de que na altura do Centenário da Independência (1922) o Brasil efetuava uma revisão de si mesmo e abria novas perspectivas, depois das transformações mundiais da Guerra de 1914-1918, que aceleraram o processo de industrialização e abriram um breve período de prosperidade para nosso principal produto de exportação, o café (CANDIDO, 1997, p. 68-69).
}

Por seu caráter questionador e também propositivo, embora a iniciativa tenha partido de um grupo de intelectuais e artistas da elite, o movimento acabou por desestabilizar comportamentos, romper padrões e abalar estruturas no meio em que gravitou. Àquela época, diga-se, esse grupo que agitou o campo das artes não poderia ser outro, visto que o acesso à educação superior e aos livros, bem como a possibilidade de viajar e alargar horizontes, eram benefícios reservados à classe dominante. E é na malha dessa contradição que podemos compreender tanto as fragilidades como o alcance das propostas modernistas.

Assim, avaliar a capacidade transformadora de suas conquistas requer considerar o papel que o movimento teve na atualização das ideias, na disseminação da nossa cultura e na valorização da língua de expressão local por meio da arte literária. Neste sentido, a rejeição de velhos parâmetros classificadores importados da metrópole e o interesse aprofundado na particularidade da vida brasileira foram passos importantes na busca de 
autonomia no campo da criação artística e literária. Em relação à língua, não por acaso, Oswald de Andrade asseverou no "Manifesto da Poesia Pau -Brasil" (1924): "Como falamos. Como somos". Em outra circunstância, por formulações da Gramatiquinha da fala brasileira, Mário de Andrade considerou a importância de não camuflar a nossa realidade, declarando: "O Brasil é um corpo espandongado, estropiado".

Outros seguiram caminhos opostos e preferiram as exaltações de fachada, a glorificação do predestinado, a exemplo do que formulou o verde-amarelismo e sua escola da anta. Por esse filão, seus proponentes (como Menotti del Picchia, Cassiano Ricardo e Plínio Salgado) pretenderam enaltecer o exótico, escamotear a realidade do país, optando por uma visada de superfície. Esse destaque, porém, não busca simplificar questões, nem mostrar a ausência de conflitos fora da conhecida polarização de ideias (pau-brasil vs. verde-amarelo; antropofagia vs. anta), no seio do movimento modernista. Como ele se processou de modo desigual, não se exclui do todo o imediatismo equivocado de alguns juízos. Apesar disso, o período áureo do movimento gerou mudanças radicais no campo da literatura brasileira e produziu obras-primas como Memórias sentimentais de João Miramar (1924), de Oswald de Andrade, e Macunaíma, o herói sem nenhum caráter (1928), de Mário de Andrade. Como força de conjunto, o movimento ganhou vigor a partir de 1930.

Com seus prós e contras, altos e baixos, nossos modernistas assumiram posições arrojadas para seu tempo. Assim, podemos conjecturar que, ao procurar sair de um estado letárgico de acomodação e atraso, negando valores do meio social de origem, parte desse grupo de rebeldes tornou-se marginal em relação a ele. Nesse ambiente em que predominava o conservadorismo de mentalidade provinciana, não é de espantar que o termo "futurismo" (usado indiscriminadamente à época) tenha se colado ao grupo de jovens como elogio e como xingamento. $\mathrm{O}$ já mencionado artigo de Oswald de Andrade, "O meu poeta futurista" (1921), que antecipadamente louvava poemas de Pauliceia desvairada, gerou polêmica e convulsionou a capital paulista. Por razões diferentes, o próprio Mário de Andrade se rebelou e rejeitou o qualificativo, afirmando que Oswald estava equivocado. Em 1922, no "Prefácio interessantíssimo", Mário reafirmou e justificou sua posição:

Não sou futurista (de Marinetti). Disse e repito-o. Tenho pontos de contato com o futurismo. Oswald de Andrade, chamando-me de futurista, errou. A culpa é minha. Sabia da existência do artigo e deixei que saísse. Tal foi o escândalo que desejei a morte do mundo. [...] (1980, p. 16). 
Essa explicação final pode dar uma dimensão do patamar de gravidade que o problema alcançou e do quanto este atingiu o artista.

O termo continuou em voga até 1925, quando o jornal $A$ Noite (Rio de Janeiro) decidiu prestar homenagem aos artistas de 22 ("Mês Futurista"), promovendo uma série de entrevistas. Entre os eleitos estava Mário de Andrade, a quem chamaram de "o papa do futurismo". Uma vez mais, Mário protestou contra a pecha, afirmando que não daria a entrevista caso ele e seus companheiros fossem identificados com a "tabuleta de futuristas". Assim, no início da conversa, quando o jornalista propôs ao escritor "- Falemos de literatura futurista [...]", Mário de Andrade rebateu: "- Já vem você com futurismo!... Fale Modernismo, que custa! E fica certo” (1983, p. 16). Desse modo, selou a designação que desejava.

Em 1944, no artigo "Gênese da Semana de Arte Moderna", Oswald irá retomar o termo que usou para elogiar a poesia nascente de Mário, que entendeu ser um importante vetor de mudança na literatura local. Na sua justificativa, esclarece: "Chamei Mário de Andrade de 'o meu poeta futurista' porque na desordem regional de seus versos vinha esse 'algo nuevo' que já era velho na Europa, mas que aqui somente assim podia exprimir uma coeva independência” (ANDRADE, 1944, p. 13). Mas, às vésperas da Semana, o alvoroço em torno do artigo de Oswald e dos poemas de Mário foi apenas um sinal de alerta para os "dias de turbilhão" que viriam em fevereiro de 1922, ano comemorativo do Centenário da Independência.

Nesse contexto, vale registrar que, coincidentemente, esse foi o ano em que se fundou no Brasil o Partido Comunista. Mas aquela pequena parcela de rebeldes provenientes da elite, que se levantava em defesa da arte nova, sequer se pronunciou a respeito, como não havia se manifestado em relação à greve geral dos operários em 1917, no Brasil, nem com respeito à Revolução Russa, ocorrida em outubro desse mesmo ano. Apesar dessa aparente indiferença às questões sociais e políticas imediatas, as mudanças que o grupo modernista propunha no campo artístico eram sintomáticas de um mundo em convulsão, de um país crivado de conflitos na sua base social, e em desordenado movimento de transformação. Um artigo de Oswald de Andrade, "O Modernismo", ilustra esse entendimento. Trata-se de um texto que foi publicado em dezembro de 1954, dois meses depois de sua morte, na revista Anhembi. Nesse balanço feito pelo artista, temos:

Se procurarmos a explicação do por que o fenômeno modernista se processou em S. Paulo e não em qualquer outra parte do Brasil, veremos que ele foi a consequência da nossa mentalidade industrial. São Paulo era de há muito batido por todos os ventos da cultura. Não só a economia cafeeira promovia 
os recursos, mas a indústria com sua ansiedade do novo, a sua estimulação do progresso, fazia com que a competição invadisse todos os campos de atividade (ANDRADE, 1954, p. 31-32).

Assim considerando, embora a Semana de Arte Moderna seja um tema já bastante explorado, voltar a ela, decorridos 90 anos dos acontecimentos, não se resume aqui a um mero ritual em homenagem aos moços de 22. O modernismo brasileiro que irrompeu de uma elite culta e prosperou no centro econômico mais avançado do país, não podemos esquecer, eclodiu num país socialmente desestruturado, a reboque das grandes potências, e que, apesar do ingresso na era industrial, continuava dependente da economia cafeeira. A equação se complica se atentarmos que integrantes desta última, a oligarquia rural, ajudaram a custear a Semana de Arte Moderna. Ainda, o país que entrava tardiamente na era do capital industrial e estava desejoso de um projeto de modernização, como antes, impunha ao coletivo uma vida quase indigente. Nesse contexto, se, de um lado, os modernistas se afastavam das manifestações públicas e da base social, de outro, sua literatura caminhava em sentido contrário. No papel singular de agitadores, também mobilizaram esforços para levar a cabo um ato em prol da arte e da cultura, com reflexos no coletivo.

$\mathrm{Na}$ argumentação de Antonio Candido,

[...] embora os escritores de 1922 não manifestassem a princípio nenhum caráter revolucionário no sentido político, e não pusessem em dúvida os fundamentos da ordem vigente, a sua atitude, analisada em profundidade, representa um esforço para retirar à literatura o caráter de classe, transformando-a em bem comum para todos. [...] Mergulharam no folclore, na herança africana e ameríndia, na arte popular, no caboclo, no proletário. Um veemente desrecalque [...] (1973, p. 164).

E, diga-se, "retirar à literatura o caráter de classe" não foi esforço de pouca monta, considerando que, no curso da Primeira República, o Brasil de 1922 contava com um índice de analfabetismo assustador cerca de 70\%, mais de dois terços da população. Esse índice mostra bem o abismo existente entre o mundo da elite e o restante da população, revelando o Brasil como um território de desigualdades e injustiças. E, neste sentido, atesta-se que a ânsia de modernização industrial não fazia o país menos perverso - a se comprovar pelas novas relações de trabalho, que deixavam à mostra suas feridas. Para além da Semana, na década de 1920, o movimento prosperou e alargou seu espectro. Bastante irregular, não escapou das contradições, nem das tendências regressivas. 
Em seu livro 1930: a crítica e o modernismo, João Luiz Lafetá consignou, logo na apresentação dos pressupostos, a presença de dois projetos (o estético e o ideológico), mais acentuados num momento do que em outro (mas não dissociados), no âmbito do movimento modernista brasileiro, explicando que o "[...] projeto estético, que é a crítica da velha linguagem pela confrontação com a nova linguagem, já contém em si o seu projeto ideológico" (2000, p. 20). Isso reafirma que mudanças no domínio da arte não podem ser dissociadas do grupo social que as produz nem do contexto histórico-social em que prosperam. Desse modo, sem excluir os problemas, entende-se que a Semana de 22 incitou e foi preparadora de um movimento reivindicador, contemplando direitos de cidadania.

Em 1942, quando Mário de Andrade traçou caminhos do movimento modernista, sintetizou seu legado em "três princípios fundamentais": "O direito permanente à pesquisa estética. A atualização da inteligência artística brasileira; e a estabilização de uma consciência criadora nacional" (1974, p. 242). Por acaso isso não seria parte da "sementeira de grandes mudanças" (a expressão é de Antonio Candido) e dos frutos que vingaram no campo da arte e da cultura? Ou, para retomar Mário de Andrade, será que, "manchando também com violência os costumes sociais e políticos", os modernistas não lutaram contra muitos preconceitos entranhados na vida local, enfrentando com ousadia a mentalidade atrasada que provinha de seu próprio meio, em benefício da comunidade?

\section{REFERÊNCIAS BIBLIOGRÁFICAS}

ANDRADE, Mário de. 1925 - Assim falou o papa do futurismo. In: Entrevistas e depoimentos. Org. Telê P. Ancona Lopez. São Paulo: T.A.Queiroz, 1983. p. 17-18. . O movimento modernista. In: Aspectos da literatura brasileira. São Paulo: Martins, 1974. p. 231-255. . Prefácio interessantíssimo. In: . Paulicéia desvairada. São Paulo; Belo Horizonte: Martins Ed.; Itatiaia, 1980. p. 16.

ANDRADE, Oswald de. Boxeurs na arena [título atribuído]. In: 22 por 22: a Semana de Arte Moderna vista pelos seus contemporâneos. Org. Maria Eugenia Boaventura. São Paulo: EDUSP, 200o. p. 85-86. . Gênese da Semana de Arte Moderna. Hoje - O mundo em letra de fôrma. [São Paulo], ano VII, n. 75, p. 13, abr. 1944.

. O Modernismo. Revista Anhembi, São Paulo, n. 9, p. 31-32, dez. 1954.

. Serafim Ponte Grande. Estabelecimento de texto Maria Augusta Fonseca. São Paulo: Globo, 2000.

BRITO, Mário da Silva. História do Modernismo Brasileiro I - Antecedentes da Semana de Arte Moderna. $2^{\underline{\underline{a}}}$ ed. revista. Rio de Janeiro: Civilização Brasileira, 1964. 
22 - Remate de Males 33.1-2

. O alegre combate de Klaxon. In: Klaxon - Mensário de Arte Moderna. Edição fac-similar. São Paulo: SCCET, 1976. s. p.

CANDIDO, Antonio. A literatura na evolução de uma comunidade; Literatura e Cultura - de 1900 a 1945. In: . Literatura e Sociedade. São Paulo: Companhia Ed. Nacional, 1973. p. 139-167; 109-138.

. Iniciação à literatura brasileira. São Paulo: Humanitas, 1997.

LAFETÁ, João Luiz. 1930: a crítica e o modernismo. São Paulo: Duas Cidades, Editora 34, 2000 .

MILLIET, Serge [Sérgio]. Uma semana de arte moderna em São Paulo. In: 22 por 22: $a$ Semana de Arte Moderna vista pelos seus contemporâneos. Org. Maria Eugenia Boaventura. São Paulo: EDUSP, 2000. p. 127-132.

SCHWARZ, Roberto. Nota sobre vanguarda e conformismo. In: O pai de família e outros estudos. Rio de Janeiro: Paz e Terra, 1978. p. 43-48. 